\title{
Air Terminal Design using Photovoltaic Panels with Energy Conservation Optimization Approach
}

\author{
Sahar Bayat*, Seyed Abbas Yazdanfar and Seyed Bagher Hosseini \\ School of Architecture and Environmental Design, Iran University of Science and Technology (IUST), Tehran, Iran
}

Received 18 Feb 2018, Accepted 21 April 2018, Available online 27 April 2018, Vol.8, No.2 (March/April 2018)

\begin{abstract}
Today, excessive consumption of fossil fuels in architecture, especially air terminals and with the increase in the number of terminals along with population growth, the energy shortage crisis in the not-so-distant future in this high-use structure predicted. Therefore, the present study aims was designing an air terminal using photovoltaic panels with an energy efficiency optimization approach. The most important energy efficiency of the sun is its direct conversion to electricity. One of the systems for direct conversion of energy from radiation to electrical energy is the photovoltaic system. Advantages of using photovoltaic panels have led to the growing use of these plates at various scales. In addition, the use of photovoltaic panels as structural elements in architecture has created innovations in the building industry and has given a new meaning to the architecture. The use of photovoltaics in terminals is a smart method to bring contemporary architecture to a new concept in green architecture. Finally, we can say that photovoltaic module has a double function in the terminal; that is, photovoltaic module also replaces conventional building materials and they produce electricity. By replacing photovoltaics, cost of materials is deducted from the total cost of the building and the cost of the photovoltaic acquisition is partially offset. Such as the integration of photovoltaics with the roof which is the best way to get the maximum efficiency of the system in which the sun is perpendicular to it.
\end{abstract}

Keywords: air terminal design, photovoltaic panels, energy efficiency optimization

\section{Introduction}

Air terminal is place that is designated for takeoff and landing aircraft. While small air terminal usually with names such as aerodrome, airfield or landing strip called. Air terminal may be created via small soil or sandy runways (one to two kilometers). Large air terminal, which is used for international flights bands are usually long asphalt and their length is several kilometers. Small and large air terminal can be equipped with traffic control tower or, if necessary, without it depends on the volume of traffic as well as investment at the air terminal region. However, at most international air terminals, flight care unit are deployed at the airport site.

Air passenger terminal is center to provide services and processing of passengers and their luggage between fighter jets and aircraft, or the transfer of passengers from aircraft to aircraft as well as for the operation of airlines companies and airport authorities and employees and managers and people, the collection design and construction was very complicated and given a new perspective is necessary

*Corresponding author's ORCID ID: 0000-0000-0000-0000 DOI: https://doi.org/10.14741/ijcet/v.8.2.37 in terms of architecture; aviation engineering has always been investigated. Passengers expect to terminal facilities and comfortable environment, beautiful, and the current work should be carried out with sufficient ease. The passenger terminal project should be efficient, smooth and helpful. It should be noted that the adoption of a logical sequence of main steps of passengers and meet the specific needs in the collection of terminals, makes it possible to reach this goal.

Today, excessive consumption of fossil fuels in architecture, especially air terminals and with the increase in the number of terminals along with population growth, the energy shortage crisis in the not-so-distant future in this high-use structure predicted.

According to the Energy Balance Sheet 2007, in Iran from 2001 to 2007, the highest consumption of petroleum products was in the transport sector and then in the construction sector (domestic, commercial, public) (Jadidi, 2015).

In this condition Iranian architecture, with its several thousand years of history, has gained valuable experience in harmony with nature and it has been implemented, but unfortunately in the last few decades there has been a deep divorce in the continuation of 
this harmony and Iran has been distancing itself from its past, it ignores the experiences of the past and rewards new scientific findings in energy optimization (Abbasi and Mohebian, 2014).

Nowadays, using the commands that have been named as the design of climate in the past, Iran's architecture can help to design modern transportation complexes to save energy.

Therefore, the objective of climate design, on the one hand, is energy saving by reducing energy consumption in the building's body which can be used to bring native architecture closer to the construction methods of indigenous peoples in each region and on the other hand, it can be used with natural and renewable energy to provide comfortable indoor conditions such as heating, cooling, ventilation and lighting. Passive solar systems, design based on the use of southern lights; control the disturbing winds of the area, positioning the shape of the site and the house, and ... more proximity with traditional concepts that are consistent with the climate that today is characterized by green architecture, sustainable architecture, and so on.

Active systems such as the use of photovoltaic cells can be used in summer for cooling systems and even in the winter, solar energy is well used and controlled by cold winds and turning off the heating equipment for hours overnight or during the day minimized. Therefore, it is proposed to use climate-friendly thinking to design a complex with consideration of energy efficiency reduction. The designer has tried to design these air terminals with regard to functional requirements and physical aspects (temperature, humidity, pressure, lighting...) and aesthetics.

The most important energy efficiency of the sun is its direct conversion to electricity. A photovoltaic system is one of the direct energy conversion systems to electrical energy. The photovoltaic is combination of the Greek word "photo" means the light and the word "volt" of the electrical energy unit. Photovoltaic cell is a plate that converts sunlight into electrical energy without animated and chemical mechanisms. Photovoltaic cells are the main component of photovoltaic systems that are made of silicon and the most flexible and the most valuable form of energy is electricity. The confidence level of these cells is very high, they do not depreciate, they do not produce pollution at all, and their energy absorption is very high. So today, using clever architectural approaches such as building architecture, the correct use or nonuse of wind of the region, the use of southern light and the lack of light in the west, such as green roofs to cool the environment and insulate the building against sound and disturbing sounds, using the wall of the trump and ... can help to reduce energy consumption. Based on this, first, with a comprehensive definition of housing, we begin the research and, at the very least, push this discussion towards design solutions to optimize energy consumption in today's buildings.

\section{The planning considerations and design of air terminal}

Passenger terminal is collection that includes aircraft between fighter jets and ways to taxi the aircraft located. Terminal is one of the key elements of airport and center to prepare service to transfer of passengers and luggage through ground access to aircraft and vice versa, from aircraft to aircraft. Decisions on the passenger terminal facilities, after collecting information from all units involved services of airlines companies and aviation operations, welfare services, airport management, employees, etc. is performed. Terminal design review and forecast needs and responding to them with respect to engineering economics and in compliance with the criteria is performed. Passengers expect a comfortable and attractive terminal facilities and effective ways to handle them; without wasting time done. For this reason, passenger terminal project should be functional and has beautiful architecture. If necessary dimensions of the various elements of the terminal along with the logical operations strengthened by appropriate marking will ensure fast move and without passengers in various stages.

\section{The role of environmental architecture in reducing fossil fuel consumption:}

The goal of climate design, on the one hand, energy saving by optimizing energy consumption in the building, which can be used to bring native architecture closer and used the construction methods of indigenous peoples in each region, and on the other hand, it can be used with natural and renewable energy to provide indoor comfort, such as heating, cooling, ventilation and lighting. Therefore, there are two goals in the compatible design of the environment: first, familiarity with native design methods and their application in design, and second, utilizing renewable energies instead of fossil fuels for heating, cooling, ventilation and lighting. Active method using energyefficient equipment, for example, turns solar energy into electricity and uses electricity. For this purpose, solar cells, solar water heaters, wind turbines and similar equipment are used in various parts of the world. In Iran, similar equipment is used. Alternatively, passive method, in fact, without the use of mechanical equipment, by moderating climatic conditions, they are using renewable energy through the proper design of the atmosphere.

The factors reducing the heat dissipation and the greater efficiency of solar energy in the design of building architecture

- it's best to place a building to collect heat from the sun in the winter on a larger front.

- materials used to form the outer shell of the building must have the highest thermal resistance. 
These include lightweight concrete (insulating concrete, gas concrete, and fine-grained concrete)

- it should be compared to the surface of the outer shell of the building to the useful object and the ratio of the surface of the roof to the useful surface of the building and reduced the level of openings in the outer shell (in door and window) to the useful surface of the building

- passive solar systems in building design can be used in summer, planting trees on the west and southwest is practically to reduce the heat input to the building

- the reflecting surfaces should be on the floor overlooking the sunblind windows; courtyard and greenhouse are connected to the empty spaces

- walls built with heavy building materials in the southern façade

- approximate area for daylight use should be $5 \%$ of the floor area.

- it is essential to use a canopy that reduces the amount of energy used to cool the building in the summer.

\section{Application of photovoltaic system in architecture}

The main component of photovoltaic systems is photovoltaic cells. Photovoltaic cells called solar cells are also known as semiconducting materials, often made of silicone, which convert light directly into electricity (Amanabadi and Maghsoudi, 2015).

Since photovoltaic cells are small and fragile and cannot generate much electricity, they put a large number of them together and make units, each of which is called a module. Modules are available in a variety of sizes. By placing some of them next to each other, photovoltaic panels are made.

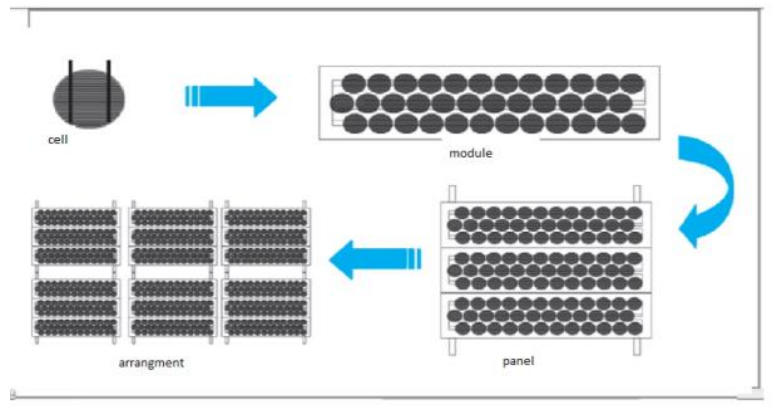

Photovoltaic panels

\section{Advantages of photovoltaic systems}

Photovoltaic systems have other benefits in addition to providing energy. Some of these benefits include:

- Photovoltaic systems don't needed from fossil fuels

- invisibility of the difference in the amount of energy produced in the best and worst place in terms of solar radiation

- High useful life
- Reducing environmental pollution

- Unlimited and availability of solar energy to convert electricity

- Ease of installation and setup, as well as don't needed to complex equipment and manpower

- Low risk of accidents like fire and explosion

- Reducing energy losses (transporting and distributing energy from the point of production to consumption will cause a huge loss of it. Using photovoltaic panels, the energy produced at the point of production is consumed, thereby reducing energy dissipation.

Advantages of using photovoltaic panels have led to its growing growth on a scale from plant to building. In addition, the use of photovoltaic panels as structural elements in architecture has created innovations in the building industry and has given new meaning to architecture. The use of photovoltaics in buildings is a smart way to bring contemporary architecture to a new concept towards green architecture.

\section{Photovoltaic methods in building, advantages and limitations}

The use of photovoltaics in buildings is done in a variety of ways. Arrangement of photovoltaic panels on the roof, installing these panels on the building and using them in the building shell, there are ways to use these panels in the building. Installing photovoltaic panels on the roof is the first and easiest way to use these panels in the building. In this way, photovoltaic panels are placed at the appropriate distance on the roof and practically do not mix with the architecture of the building; therefore, they do not play a role in creating the beauty of the building.

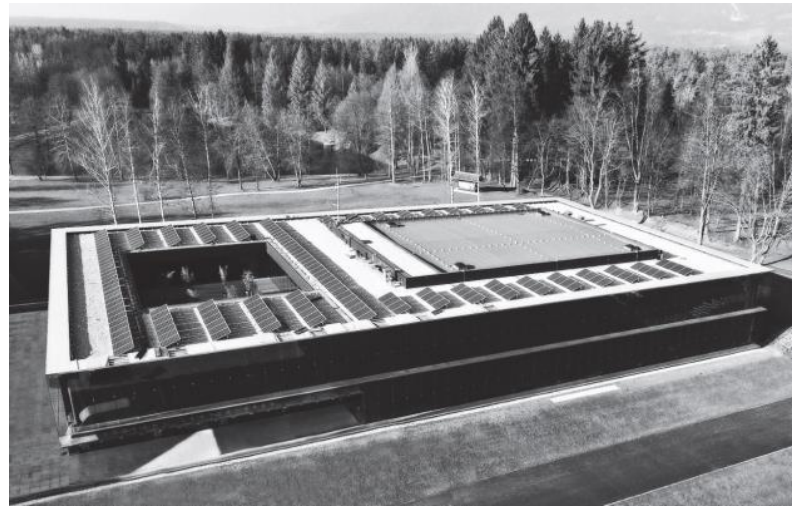

Install photovoltaic on the roof

\section{Install photovoltaic panels on the building}

In this method, systems consisting of photovoltaic panels with an underline and a fastening on the building are installed. This method involves a significant increase in the weight of the building, the increase in wind load and the destruction of the shell of the building. In commercial buildings or lightweight 
structures, the weight gain imposed on the ceiling should also be calculated from the photovoltaic plate load, especially if the building is old or have a lightweight structure.

In addition, with increasing components installed to a level, the load on the wind enters it. Therefore, in systems with photovoltaic panels installed on the building, the connections of the plates should be in such a way as to withstand extreme winds. The destruction of the building shell is another disadvantage of the photovoltaic attachment to the building, because the penetration of water increases by creating a hole in the roof of the building for the installation of photovoltaic panels. Of course, today it is possible to permanently seal these holes, but due to increased costs, there is no economic justification. The combination of photovoltaic panels with a building shell is the most recent photovoltaic method in the building. Photovoltaic integration with building briefly called integrated photovoltaic is now described in detail in this study.

- The use of photovoltaic modules in the wall of the building and the removal of part of the cost of the wall

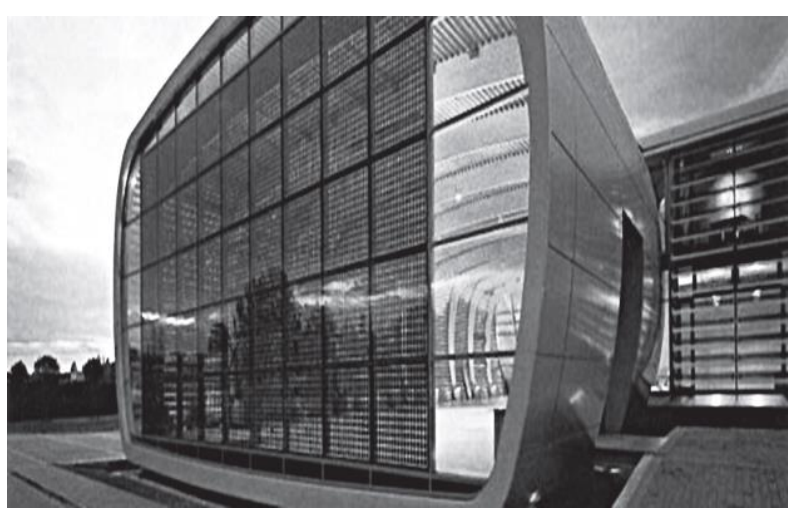

Photovoltaic application with building shell

\section{Comparison of the types of cells and modules used in the combined photovoltaic}

In the integrated photovoltaic system, different types of modules can be used, depending on their type of function; framed classical modules, flexible crystalline film or thin film on metal layer, roof tile in combination with solar cells, transparent monocrystalline modules, colored cell modules, shapeless modules (Amorphous), semitransparent mesh...

All components of the modules are made on the order of the employer. This order includes the shape of the module, type and color of the cell, transparency of the cell, layers, and size of the modules, characteristics of the isolated sound and heat, modulus voltage and its ultimate power.

\section{Combination of photovoltaics with roof}

Integrated photovoltaic systems were first used in building roofs. In this type of integration, the best mode for maximizing system efficiency is that the slope of the photovoltaic interconnected roof is such that the sun perpendicular to it:

But nowadays, it is possible to combine flat roof with photovoltaic plates; however, the roof of the sun's angle of facade varies according to the geographic and temporal position.

The optimum angle is calculated based on the time to get the maximum energy in different areas. Saw teeth are preferable to flat roofs (Nerbert, 2006). The use of roof tiles and thin-walled photovoltaics of these potters is a novel combination of photovoltaics with roofs. In the case of photovoltaic combinations with the roof of the building, the space below should be ventilated to allow cooling system. In winter, the heat generated by the system is used to heat the indoor space. Ventilation of combined PV systems in the roof is easier than facade systems; in these systems, the unfavorable heat received from the PV plates is higher than individuals, and consequently, they have less effect on the facade systems.

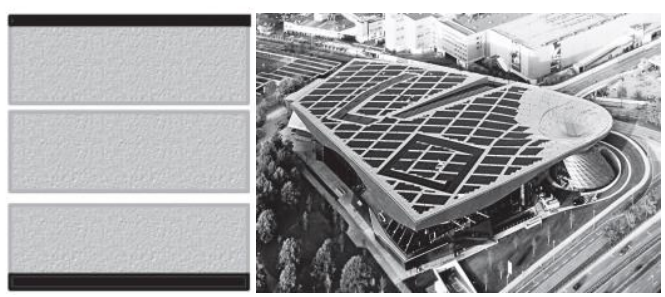

Flat roof

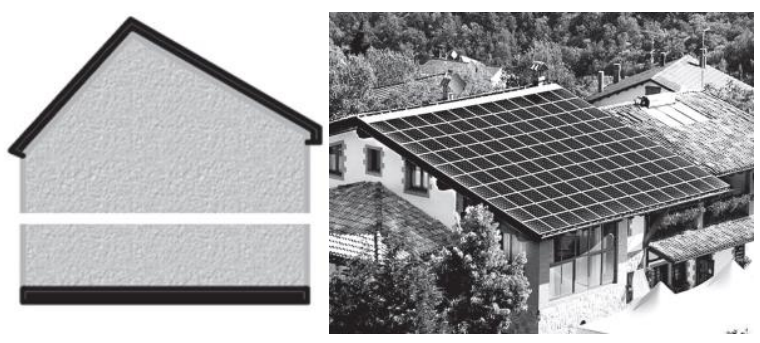

Sloping roof

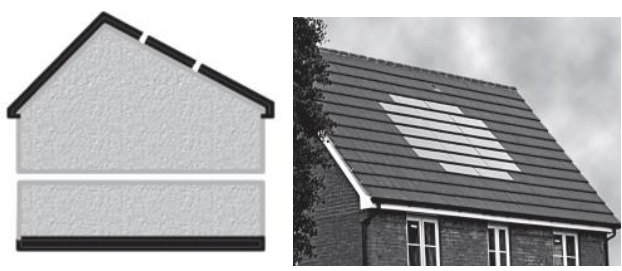

Sloping roof in combination with tiles
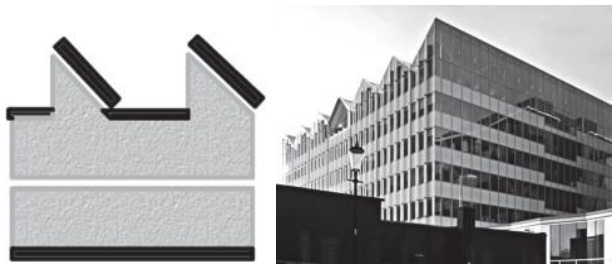

Saw teeth roof with north skylight 

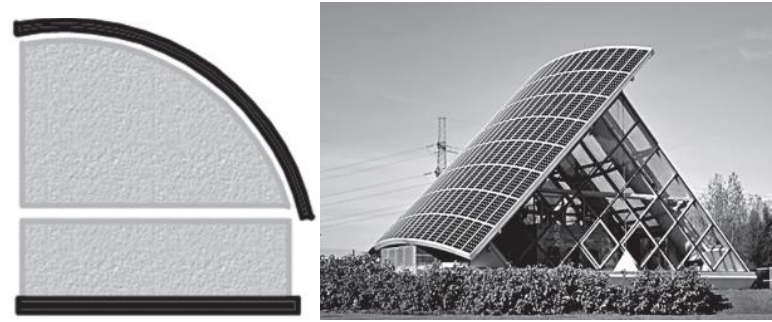

Roof / curved walls

\section{Integration in facade}

Integrated photovoltaic in the facade, after the roof, is the most common form of integration in the building, and is often used in southern, eastern and western facade. This integration is done in two ways: creating a curtain and a covering wall.

It is important to note that if the altitude from the viewpoint is in the shade for any reason, including being located in densely populated or densely populated areas, Photovoltaics should not be used at this height. Photovoltaics should only be used at altitudes above the shaded area; in addition, as a combination of facilities in the roof, there should be space to cool it (Nerbert, 2006). With the ventilation of the empty space between the photovoltaic shell and the building, it is possible to increase the efficiency of the cells.
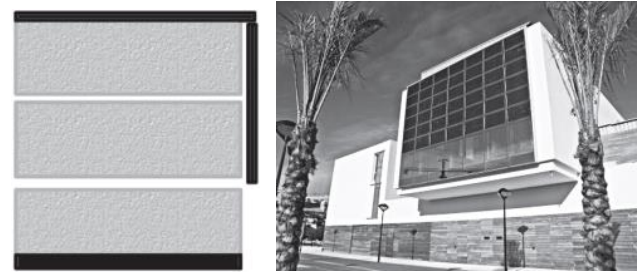

Vertical wall
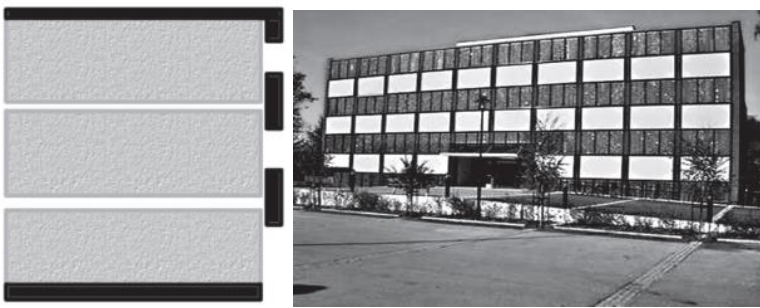

Vertical wall with window

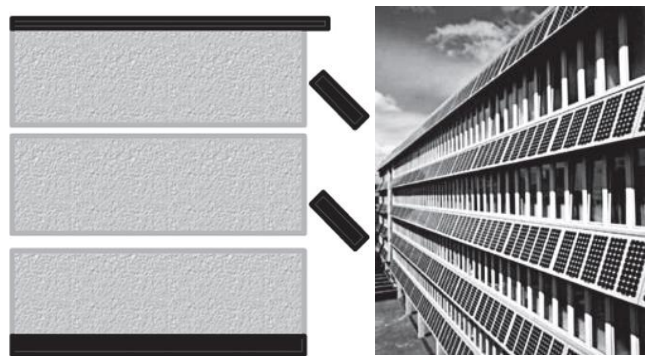

Steep Pv and window
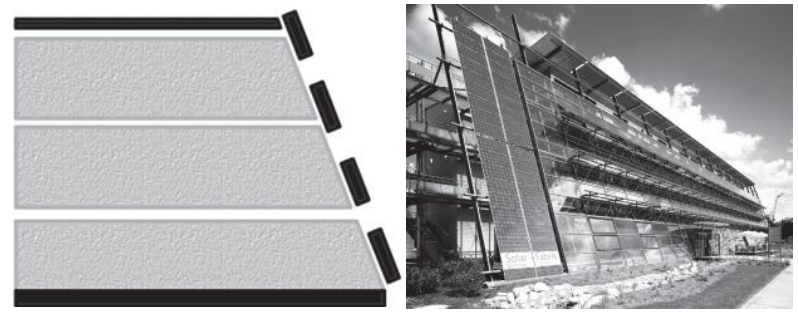

Walls with vertical windows

\section{Case sample}

BP solar shell in Norway: The BP's solar shell is a hybrid of two new building concepts: the two-shell external façade in the modernization and integrated photovoltaic projects. As we see in the figure, two-shell façade is a glass wall connected to the outside of the building's exterior. It is separated by an air distance of $0.8 \mathrm{~m}$ apart, and its thermal performance is similar to the glass atrium. The interface reduces heat dissipation in the main view and reduces the heat load of the building in the winter. In the summer, this space is ventilated with a hole at the top of the secondary shell. Photovoltaic cells are placed in transparent glass modules and thus provide the possibility of using natural light. This system is connected to the network and transmits power to the network if it is not needed.

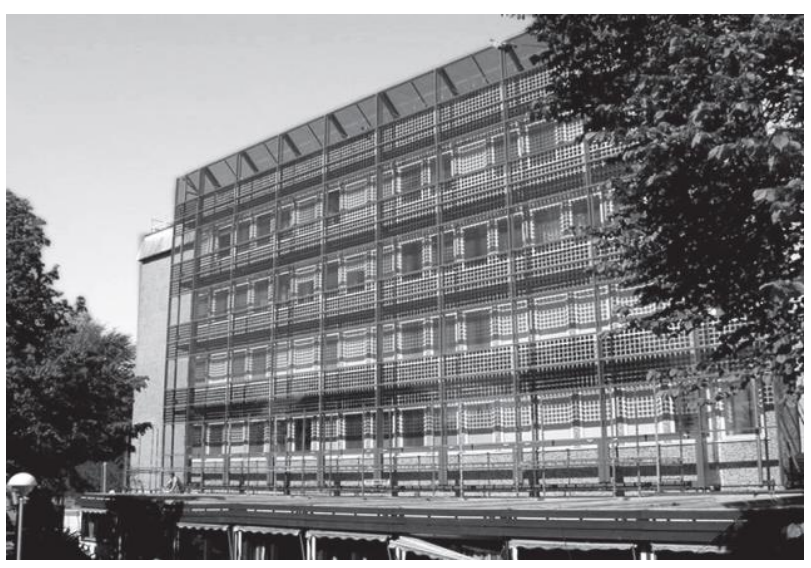

Photovoltaic application: integration in the façadetransparent screen wall

\section{Photovoltaic integration in shadows}

Photovoltaic integration in the shadows is one of the most ingenious and, of course, intelligent applications of this system. According to many experts, photovoltaic integration in the shadows is the most appropriate photovoltaic application in the building, because the shadows are often exposed to sunlight by their very nature and if integrated with photovoltaic panels with a tilt angle, they will receive the most suitable radiation and have the best return. Therefore, the use of photovoltaic panels in combination with shading, whether it's independent or in combination with the building, is very common. These shadows can be dark or transparent. 


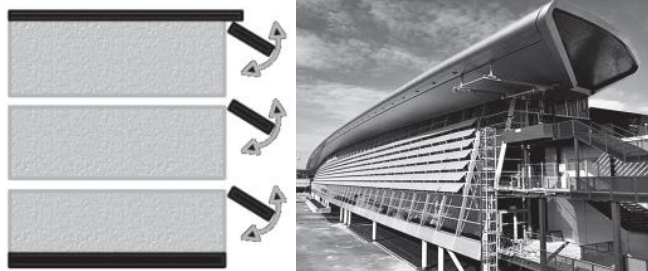

Moving shadows

\section{Design considerations for integrated photovoltaic}

The control of increasing the temperature of photovoltaic panels and also the amount of shading on these panels has a significant effect on their efficiency. Therefore, the design should be such as to allow adequate ventilation for photovoltaic panels and, as far as possible, avoid shadowing on these panels. Therefore, designers should pay attention to the following photovoltaic design:

Examine the shaded areas of the building before designing

Considering ventilation modules at design time Integrated photovoltaic system components

Panel or solar panel: A panel or solar panel transforms sunlight into direct electricity.

Group connect box: A grouping box connects panels to the electrical circuit and protects solar panels against lightning and electricity.

Metal or construction structures: Metal or construction structures are the holder of panels in a specific direction and angle.

Controller device: controller has the task of controlling power generation, power consumption, charging the storage batteries and adjusting the specifications of the power and outputs in terms of voltage and ampere.

Communication cables: communication cables connect photovoltaic system to electrical circuits.

Storage batteries: storage batteries store the power needed at cloudy condition.

Direct-to-alternating current converter: converter directly transforms the current of solar panel into a phase-to-phase or three-phase alternating current. Regardless of photovoltaic panels that integrate with the building, all the components in this system are easily placed in a small space, so there is not much space in this system. If an integrated photovoltaic system is connected to the network, the space required by removing the batteries is reduced.

\section{Integrated photovoltaic in Iran}

Despite the global requirements for the use of renewable energy, benefits of integrated photovoltaic as well as the unique potential of Iran for the use of solar energy, unfortunately, this technology is still unknown in the country. Below refer to most important factors in the non-proliferation of integrated photovoltaic in Iran.

\section{Unreasonable cost of energy in Iran}

In Iran, the energy generated from computer fossil sources comes at a negligible cost to the consumer However, energy from renewable sources such as solar energy, wind, biomass, etc., it involves a great deal of expenses, including research and development costs, preparatory support, economic development and affiliated industry, protection and care technology, and tax deductions. Iran's conventional energy prices, such as fossil fuels, are not the true price, and to calculate their core prices, other costs should not be considered in our country. The most important of these costs are the environmental and social costs imposed on citizens, ecosystems and natural resources. The cost of saving fossil fuels for a kilowatt-hour for electricity generated from photovoltaic systems is about 410.9 Rials per kilowatt-hour (World Economic Newspaper, 2010)

\section{Site Design}

- Initial plan taken from chilipa in Iranian architecture and the evolutionary development process of the project in accordance with the values of the Iranian-Sasanian architecture.

- The distribution of the chilipa form and its cellular degradation, then the binary combination or several forms created to create a stable form of the basic plan of the design.

- The entrance lobby section is also retrieved from the chlipa form by looking at the Iranian octagon entrance. The two-chilipa combination has become eight turns instead of four and has eight paradises with him. The octagon of the center of the circular chilipa (core chippa) turns out from it and produces an Iranian octopus to invite passengers and the expression of the history of Iranian architecture for international travelers, which can be said openly, provides a form of sustainability in architecture.

- A tent structure on the entrance door for public use from the roof of the terrace and create user for that space- coffee shop- inspired by Iranian tents and tribal tents and the creation of six arcs from the Iranian arches and arch of the Sasanian period.

- The water inside the entrance hall is taken from the egg form, which can be said to be the most stable and well-known structural form in the world. As well as the production of arches that house the Iranian architecture and the transparency of the form has also created a secret inner appearance.

- Ultimately, the final form of the project according to previous speeches, follow from the finger design form of the air terminals. 
Chilipa multiple combination and cell analysis to create form

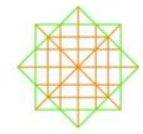

1

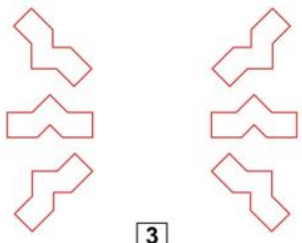

3

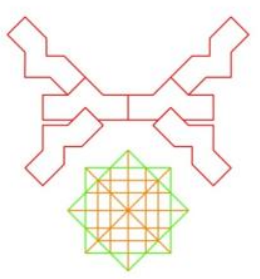

5

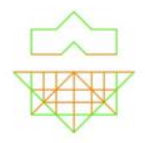

2

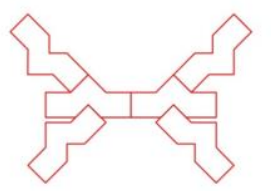

4

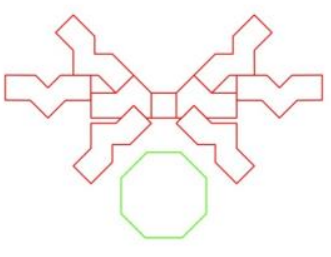

6
Use fingers pattern to design terminals
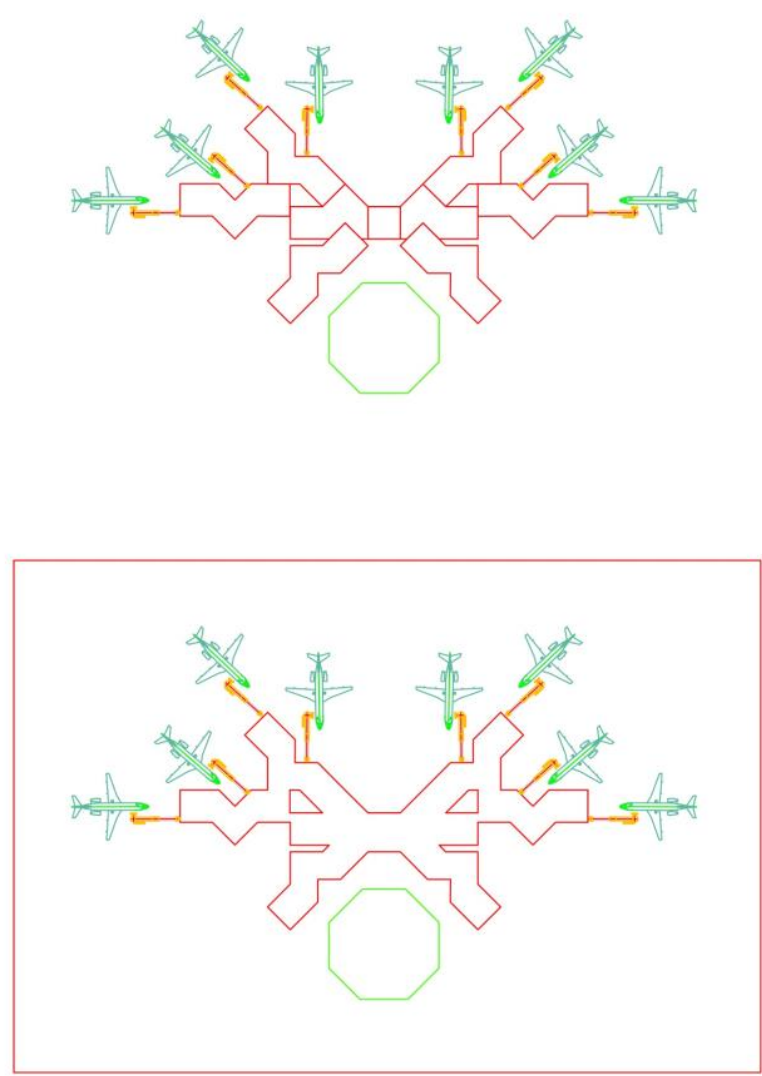

Façade of the terminals entrance
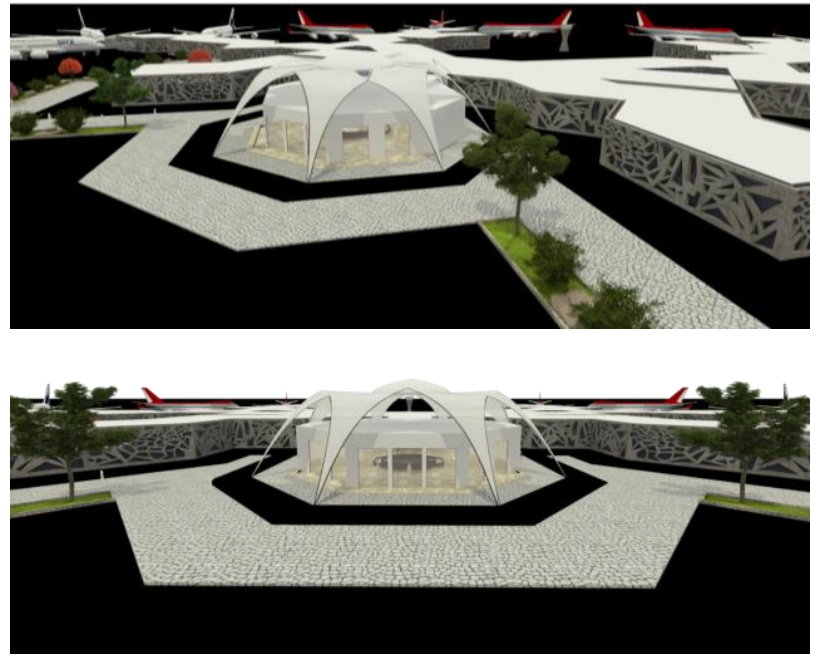

Facade of the entrance hall and its tent structure

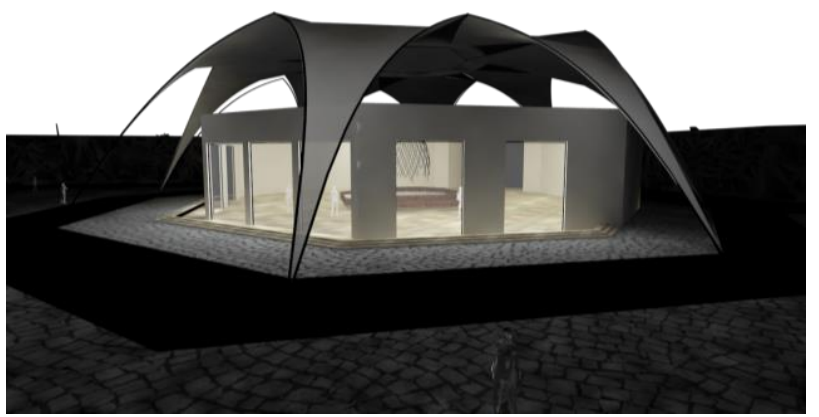

Conclusion

- Designing dense transport sets and appropriate orientation for solar thermal usage and protection against cold winds such as south-facing edges that have the most energy of the sun.

- The main component of photovoltaic systems is photovoltaic cells. Photovoltaic cells called solar cells (also known as solar cells) are also known. These cells are made of semiconducting materials, often made of silicone, which convert light directly into electricity.

- Photovoltaic systems have other benefits in addition to providing energy. Some of these benefits include:

○ photovoltaic systems don't needed from fossil fuels

$\circ$ invisibility of the difference in the amount of energy produced in the best and worst place in terms of solar radiation

- reducing environmental pollution

o unlimited and availability of solar energy to convert electricity

$\circ$ ease of installation and setup, as well as don't needed to complex equipment and manpower

- low risk of accidents like fire and explosion reducing energy dissipation

photovoltaic integrated in the building, ie using photovoltaic with building shell. In this method, photovoltaic module has a double functional effect in the building; 
In this sense, photovoltaic module also replaces conventional building materials and produce electricity. By replacing photovoltaics, the cost of materials is deducted from the total cost of the building and the cost of the photovoltaic acquisition is partially offset. Such as photovoltaic integration with the roof, which is the best way to get the maximum efficiency of the system and the sun, is shine to it perpendicularly and the other is a facade, especially in the southern facade, combined with the shades and balcony balconies are also other types of the system.

\section{References}

Energy saving in residential buildings, research and review department of Rah-e-Shahr Consulting Engineers, spring 1995

Compound Photovoltaic, Energy in the Architecture, International Rah-e-Shahr Group, No. 118, Summer 2010

Book of Sustainable Architecture, Seyed Ehsan Sayadi, Fall 2011

Jaleh and Fatemeh Jafarpour (2010). Reduce the cost of building and architectural design of residential buildings

The role of architectural design in reducing energy consumption in the building, Applied Scientific Applied Center of Rah-e-Shahr International Group (Quick Build), Research and writing by Dr. Mansoureh Tahbaz, Shahrbanoo Jalilian, No. 123, Spring 2011

The role of architectural design in reducing energy consumption in buildings (wind energy in architecture), Applied Scientific Research Center of Rahahr International Group (Quichel Bild), Research and writing by Dr. Mansoureh Tahbaz Khanum, engineer of Banoo Jalilian, No. 129, Spring 2011

Nahid Abbasi, Jalal Mohebian (2014). Sufeh Journal, Shahid Beheshti University, No. 43, Autumn and Winter 2006
Abbas Jadidi (2015). The role of architectural design in reducing energy consumption in buildings, International Center for Applied Scientific Education, Rah-e-Shahr International Group (Kuwait Bild), No. 123

Aman Abadi, Marzieh. Maghsoudi, Ehsan, (2015). The process of using and developing wind and solar energy in Iran and elsewhere in the world

Lucker, Nerbert (2006), Heating, Cooling, Lighting, Design Approaches for Architects, Translated by Dr. Mohammad Ali Kinejad, Rahman Azari, Islamic Art University Press Tabriz

The World Economic Journal, No. 1965, The Necessity of Using Clean Energy, p. 28, 19/9/2010

Social Dimension of Housing, Abbas Mahmoudi

Architectural Standards, Nouifert

Structural and Massive Behaviors, Mohammad Reza Araghchian

Book Design of Climate, Dr. Vahid Ghobadian

The book of the traditional building, Dr. Vahid Ghobadian

Residential Complexes, Seyyed Javad Safinejad

Optimum housing, Firooz Mojour

Environment of the city, Hussein Shokouhi

Neighborhood in urbanization, Mina Motie Nejad

Housing and development program, Hamideh Mirzadeh

Introduction to the Design of the Site, Zohreh Daneshpour

Journal of Consulting Engineers

The Role of the Government in the Development of Housing, Amena Safor

A quick look at some of Iran's housing companies, Hassan Beig Mohammadi

A Brief Look at the Dilemma of Housing in Iran, Ardeshir Molaee

Eiffert، Patrina، Kiss، Gregory (2000) “Building-Integrated Photovoltaic Designs for Commercial and Institutional Structures”،NREL 